\title{
Unified magnifying endoscopic classification for esophageal, gastric and colonic lesions: a feasibility pilot study
}

\section{다)(우 $\odot$}

\begin{abstract}
Authors
Haruhiro Inoue, Mary Raina Angeli Fujiyoshi, Akiko Toshimori, Yusuke Fujiyoshi, Yuto Shimamura, Mayo Tanabe, Yohei Nishikawa, Yuichiro Mochizuki, Takuki Sakaguchi, Ryusuke Kimura, Shinya Izawa, Haruo Ikeda, Manabu Onimaru, Naoyuki Uragami
\end{abstract}

Institution

Digestive Diseases Center, Showa University Koto Toyosu Hospital, Tokyo, Japan

submitted 5.10.2020

accepted after revision 20.4.2021

\section{Bibliography}

Endosc Int Open 2021; 09: E1306-E1314

DOI 10.1055/a-1499-6638

ISSN 2364-3722

(c) 2021. The Author (s).

This is an open access article published by Thieme under the terms of the Creative Commons Attribution-NonDerivative-NonCommercial License, permitting copying and reproduction so long as the original work is given appropriate credit. Contents may not be used for commercial purposes, or adapted, remixed, transformed or built upon. (https://creativecommons.org/licenses/by-nc-nd/4.0/)

Georg Thieme Verlag KG, Rüdigerstraße 14,

70469 Stuttgart, Germany

\section{Corresponding author}

Mary Raina Angeli Fujiyoshi, MD, Digestive Diseases Center, Showa University Koto Toyosu Hospital, 5-1-38 Toyosu, Kotoku, Tokyo 135-8577, Japan

Fax: +81-3-6204-6396

raina.abadmd@gmail.com

\section{ABSTRACT}

Background and study aims Image-enhanced magnifying endoscopy allows optimization of the detection and di- agnosis of lesions found in the gastrointestinal tract. Current organ-specific classifications are well-accepted by specialized endoscopists but may pose confusion for general gastroenterologists. To address this, our group proposed the Unified Magnifying Endoscopic Classification (UMEC) which can be applied either in esophagus, stomach, or coIon. The aim of this study was to evaluate the diagnostic performance and clinical applicability of UMEC.

Patients and methods A single-center, feasibility pilot study was conducted. Two endoscopists with experience in magnifying narrow band imaging (NBI), blinded to whitelight and non-magnifying NBI findings as well as histopathological diagnosis, independently reviewed and diagnosed all images based on UMEC. In brief, UMEC is divided into three categories: non-neoplasia, intramucosal neoplasia, and deep submucosal invasive cancer. The diagnostic performance of UMEC was assessed while using the gold standard histopathology as a reference.

Results A total of 303 gastrointestinal lesions (88 esophageal squamous lesions, 90 gastric lesions, 125 colonic lesions) were assessed. The overall accuracy for both endoscopists in the diagnosis of esophageal squamous cell cancer, gastric cancer, and colorectal cancer were $84.7 \%$, $89.5 \%$, and $83.2 \%$, respectively. The interobserver agreement for each organ, Kappa statistics of $0.51,0.73$, and 0.63 , was good.

Conclusions UMEC appears to be a simple and practically acceptable classification, particularly to general gastroenterologists, due to its good diagnostic accuracy, and deserves further evaluation in future studies.

\section{Introduction}

Advancement of endoscopic imaging technologies in the recent years has led to the development of image enhanced endoscopy (IEE). Although histopathological examination remains the gold standard for the diagnosis of lesions found in the gastrointestinal (GI) tract [1], IEE allows optimization of the detection and diagnosis of dysplasias and cancers. More commonly applied IEE technologies are magnifying endoscopy with narrow band imaging (NBI) and chromoendoscopy [2].

To date, several diagnostic classifications have been advocated due to the high diagnostic performance of each criteria, causing some confusion among endoscopists as to which classification to use. To address this, each society or expert team moved to unify and reorganize the past advocated classifications. For esophagus, Inoue's Classification (2000) and Arima Classification (2004) have been unified into the Japan Esopha- 
geal Society (JES) magnifying endoscopic classification (2012). For stomach, the Vascular Surface (VS) Classification (2001) [3] was rearranged to Magnifying endoscopy simple diagnostic algorithm for early gastric cancer (MESDA-G) (2016) [4]. For the colon, Sano's classification (2006) [5, 6], Hiroshima (2008) [7], Showa (2009) [8], Jikei (2009) [9], NBI international colorectal endoscopic (NICE) $(2010)[10,11]$ were proposed to be unified into Japan NBI Expert Team (JNET) classifications (2016) [12]. However, these diagnostic criteria still differ between each organ by having different categorizations. Current organ-specific classifications are well-accepted by specialized expert endoscopists but may still pose confusion for general gastroenterologists.

Bearing this in mind, the idea of generalizing the practical use of image enhanced magnifying endoscopy diagnostic criteria seemed quite appealing, hence, our group proposed the Unified Magnifying Endoscopic Classification (UMEC) which can be applied either in esophagus, stomach, or colon. In brief, we simplified the magnifying endoscopic classification by dividing into three categories: Non-neoplastic, intramucosal neoplasia, and deep submucosal invasive cancer. The aim of this feasibility pilot study was to evaluate the diagnostic performance of UMEC using our clinical data.

\section{Methods}

\section{Study population}

This was a retrospective analysis of data collected prospectively at a single tertiary referral center, Showa University Koto Toyosu Hospital, Tokyo, Japan between April 2014 and March 2020. Endoscopic images from patients who underwent magnifying $\mathrm{NBI}$ examination of the esophagus, stomach, and colon were reviewed.

\section{Image selection and data analysis}

In this feasibility study, endoscopic images of patients who underwent magnifying NBI of the esophagus, stomach and colon were retrieved. Of these, only cases with corresponding histopathological results were selected and included. Images were then grouped based on the histopathological diagnosis and separate folders per case were created. Subsequently, whitelight and non-magnifying images were deleted, and an all-magnifying NBI image catalog was created. Image quality was assessed by rating each image from 1 to 5 , and was based on the clarity of the visual field and the microvascular structure (1 being the lowest quality - blurred/unclear visual field with obscured microvascularity, and 5 having the highest quality clear visual field with no obstruction, clear microvascularity). Images with ratings of 1 or 2 from the evaluators were excluded from this study.

Two magnifying NBI images were selected per case and inserted into PowerPoint (Windows 2010; Microsoft, Santa Clara, California, United States) presentation slides against a black background while preserving the file size, format and image quality. Each case was assigned a number and subsequently arranged randomly according to random number tables created by Excel (Windows 2010; Microsoft).
Randomized magnifying NBI images were then assessed separately by two endoscopists, with experience in magnifying $\mathrm{NBI}$, who were blinded to patients' clinical information, whitelight and non-magnifying NBI findings as well as histopathological results. In this study, an expert endoscopist was defined as an endoscopist who specialized in a specific organ and was a board-certified trainer of the Japan Gastroenterological Endoscopy Society. A general gastroenterologist (non-expert endoscopist) was defined as an endoscopist who did not specialize in a specific organ even if he or she had experience with magnifying NBI. The two endoscopists who participated in this study were considered as non-experts.

Biopsy specimens were available for all cases, however, for carcinomas, histopathologic diagnosis was made on endoscopically or surgically resected specimens. Specimens were fixed in paraffin, stained with hematoxylin and eosin, and evaluated by an expert pathologist in our institution. The expert pathologist diagnosed the specimens according to the following: 1) esophageal specimens - Japanese Classification of Esophageal Cancer, $11^{\text {th }}$ edition, 2) gastric specimens - Japanese Classification of Gastric Carcinoma, $15^{\text {th }}$ edition, and 3) colonic specimens Japanese Classification of Colorectal, Appendiceal and Anal Carcinoma, $9^{\text {th }}$ edition. The accuracy of UMEC-based diagnosis was assessed while using the gold standard histopathology as a reference.

\section{Unified magnifying endoscopic classification (UMEC)}

Through an adaptation of previous classifications for each respective organ (JES Classification for esophagus, VS Classification and MESDA-G for stomach, and JNET Classification for coIon), UMEC was created as follows ( $\triangleright$ Table 1 ).

Esophagus: UMEC diagnosis for the esophagus was categorized according to the characteristics of intrapapillary capillary loop (IPCL) pattern and can be classified intothree3 groups ( Fig.1). E-UMEC 1 was considered non-neoplastic, E-UMEC $2 \mathrm{~A}$ as inflammation and low-grade intramucosal neoplasia, UMEC 2B as high-grade intramucosal neoplasia and intramucosal cancer, and E-UMEC 3 as invasive cancer.

Stomach: UMEC diagnosis for the stomach was made by assessing the presence or absence of demarcation line (DL), irregular microvascular pattern (IMVP) and irregular microsurface pattern (IMSP), and was based on an adaptation of the VS Classification and MESDA-G. In brief, S-UMEC 1/2A were considered as non-cancer and S-UMEC $2 \mathrm{~B} / 3$ as cancer ( $\mathbf{F i g . 2}$ ). For the stomach, S-UMEC 1 and $2 \mathrm{~A}$ were not divided because there was not enough evidence that non-neoplastic and adenoma can be distinguished just by using image enhanced magnifying endoscopy. Similarly, S-UMEC 2B and 3 were not divided because there was not enough evidence that image enhanced magnifying endoscopy is clinically useful to diagnose the depth of invasion.

Colon: UMEC for the colon followed the JNET classification, which uses magnifying NBI observation with a focus on vessel and surface patterns to diagnose colorectal tumors as C-UMEC 1, 2A, 2B and 3 ( Fig. 3). C-UMEC 1, 2A, 2B, and 3 correlate with the pathological diagnosis of hyperplastic polyp and ses- 
- Table 1 Outline of UMEC

\begin{tabular}{|c|c|c|c|c|c|}
\hline & & \multirow[t]{2}{*}{ UMEC1 } & \multicolumn{2}{|l|}{ UMEC2 } & \multirow[t]{2}{*}{ UMEC3 } \\
\hline & & & UMEC2A & UMEC2B & \\
\hline \multirow{2}{*}{\multicolumn{2}{|c|}{ Expected histology }} & \multirow{2}{*}{$\begin{array}{l}\text { Non-neoplastic } \\
\text { lesion }\end{array}$} & \multicolumn{2}{|l|}{ Intramucosal neoplasia } & \multirow{2}{*}{$\begin{array}{l}\text { Deep submucosal invasive } \\
\text { cancer }\end{array}$} \\
\hline & & & $\begin{array}{l}\text { Benign } \\
\sim \\
\text { low grade neoplasia }\end{array}$ & $\begin{array}{l}\text { High-grade neoplasia } \\
\sim \\
\text { Intramucosal cancer } \\
\text { (shallow submucosal cancer) }\end{array}$ & \\
\hline \multicolumn{6}{|l|}{ Esophagus } \\
\hline & & E-UMEC1 & E-UMEC2A & E-UMEC2B & E-UMEC3 \\
\hline \multirow[t]{2}{*}{$\begin{array}{l}\text { Endoscopic } \\
\text { finding }\end{array}$} & $\mathrm{IPCL}$ & $\begin{array}{l}\text { Normal IPCL } \\
\text { (The caliber of } \\
\text { the vessels is } \\
\text { about } 7-10 \mu \mathrm{m} \text { ) }\end{array}$ & $\begin{array}{l}\text { Abnormal microvessels } \\
\text { without severe irregularity } \\
\text { (The caliber of the vessels is } \\
\text { about } 7-10 \mu \mathrm{m} \text { ) }\end{array}$ & $\begin{array}{l}\text { Abnormal microvessels with } \\
\text { severe irregularity or highly } \\
\text { dilated abnormal vessels } \\
\text { (The caliber of the vessels is } \\
\text { around } 20 \mu \mathrm{m} \text { ) }\end{array}$ & $\begin{array}{l}\text { Highly dilated vessels } \\
\text { which calibers appear to } \\
\text { be more than three times } \\
\text { that of usual E-UMEC2B } \\
\text { vessels } \\
\text { (The caliber of the vessels } \\
\text { is often }>60 \mu \mathrm{m} \text { ) }\end{array}$ \\
\hline & AVA & - & - & $\begin{array}{l}\text { AVA-small, middle } \\
\text { (smaller than } 3 \mathrm{~mm} \text { ) }\end{array}$ & $\begin{array}{l}\text { AVA-large } \\
\text { ( } 3 \mathrm{~mm} \text { or larger) }\end{array}$ \\
\hline \multicolumn{2}{|c|}{$\begin{array}{l}\text { Expected histology } \\
\text { (invasion depth) }\end{array}$} & $\begin{array}{l}\text { Normal epithe- } \\
\text { lium }\end{array}$ & Inflammation and LGIN & $\begin{array}{l}\text { HGIN and SCC } \\
\text { (T1a-EP, T1a-LPM, T1a-MM, } \\
\text { T1b-SM1) }\end{array}$ & $\begin{array}{l}\text { invasive SCC } \\
\text { (T1b-SM2 or deeper) }\end{array}$ \\
\hline \multicolumn{6}{|l|}{ Stomach } \\
\hline & & \multicolumn{2}{|l|}{ S-UMEC $1 / 2 \mathrm{~A}$} & \multicolumn{2}{|l|}{ S-UMEC 2B/3 } \\
\hline \multirow{2}{*}{$\begin{array}{l}\text { Endoscopic } \\
\text { finding }\end{array}$} & $\mathrm{DL}$ & Absent & Present & \multicolumn{2}{|l|}{ Present } \\
\hline & $\begin{array}{l}\text { Vascular } \\
\text { and sur- } \\
\text { face }\end{array}$ & - & Regular & \multicolumn{2}{|c|}{$\begin{array}{l}\text { Irregular microvascular pattern and/or Irregular microsurface } \\
\text { pattern }\end{array}$} \\
\hline \multicolumn{2}{|c|}{ Expected histology } & \multicolumn{2}{|l|}{ Non-cancer } & \multicolumn{2}{|l|}{ Cancer } \\
\hline \multicolumn{6}{|l|}{ Colon } \\
\hline & & C-UMEC1 & C-UMEC2A & C-UMEC2B & C-UMEC3 \\
\hline \multirow[t]{2}{*}{$\begin{array}{l}\text { Endoscopic } \\
\text { findings }\end{array}$} & Vessel & Invisible & $\begin{array}{l}\text { Regular caliber } \\
\text { Regular distribution }\end{array}$ & $\begin{array}{l}\text { Variable caliber } \\
\text { Irregular distribution }\end{array}$ & $\begin{array}{l}\text { Loose vessel areas } \\
\text { Interruption of thick ves- } \\
\text { sels }\end{array}$ \\
\hline & Surface & $\begin{array}{l}\text { Regular dark } \\
\text { White spots } \\
\text { similar to sur- } \\
\text { rounding nor- } \\
\text { mal mucosa }\end{array}$ & $\begin{array}{l}\text { Regular (tubular/branched/ } \\
\text { papillary) }\end{array}$ & Irregular or obscure & Amorphous areas \\
\hline \multicolumn{2}{|c|}{ Expected histology } & $\begin{array}{l}\text { Hyperplastic } \\
\text { polyp } \\
\text { Sessile serrated } \\
\text { lesion (SSL) }\end{array}$ & $\begin{array}{l}\text { Adenoma } \\
\text { Low-grade dysplasia }\end{array}$ & $\begin{array}{l}\text { High-grade dysplasia/mucosal } \\
\text { cancer } \\
\text { Shallow SM invasive cancer }\end{array}$ & Deep SM invasive cancer \\
\hline
\end{tabular}

UMEC, Unified Magnifying Endoscopic Classification; IPCL, intrapapillary capillary loop; AVA, avascular area; LGIN, low-grade intramucosal neoplasia; EP, epithelium; LPM, lamina propria mucosa; MM, muscularis mucosa; SM, submucosa; HGIN, high-grade intramucosal neoplasia SCC, squamous cell carcinoma; DL, demarcation line.

sile serrated polyp, low-grade intramucosal neoplasia, non-invasive high-grade neoplasia/intramucosal carcinoma/carcinoma in situ (Tis), and superficial submucosal invasive carcinoma (SM-s: T1a; <1,000 $\mu \mathrm{m}$ ), and deep submucosal invasive carcinoma (SM-d: T1b; $\geq 1,000 \mu \mathrm{m})$, respectively.

\section{Statistical analysis}

Sensitivity, specificity, positive predictive value, negative predictive value, accuracy for diagnosis of three categories - nonneoplastic, intramucosal neoplasia, and deep submucosal invasive cancer - were calculated separately for each endoscopist. 

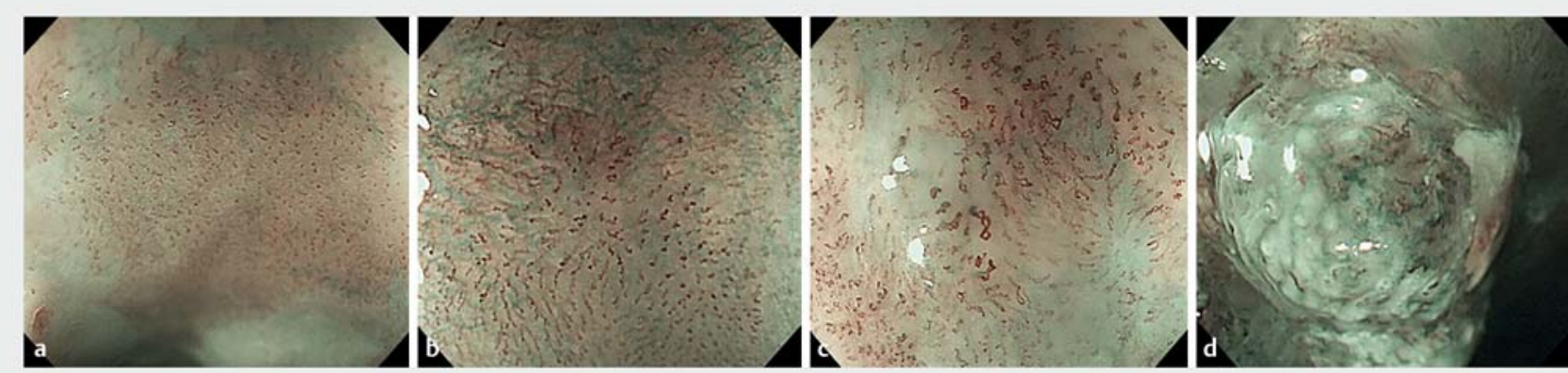

- Fig. 1 UMEC for esophagus (E-UMEC). a E-UMEC 1 are considered non-neoplastic, b E-UMEC $2 \mathrm{~A}$ as inflammation and low-grade intramucosal neoplasia, c UMEC 2B as high-grade intramucosal neoplasia and intramucosal cancer, and d E-UMEC 3 as invasive cancer.

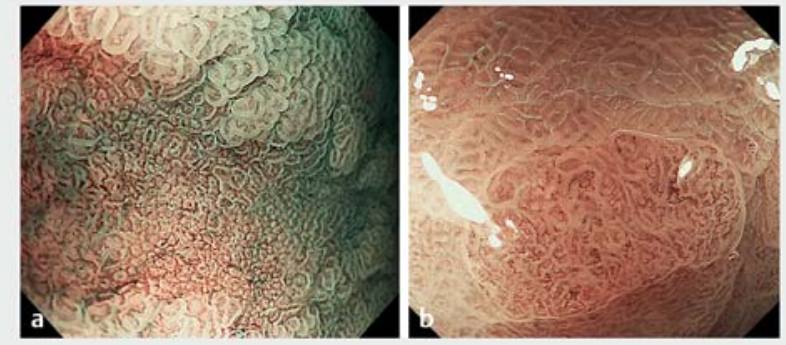

Fig. 2 UMEC for stomach (S-UMEC). a S-UMEC 1/2A are considered as non-cancer and $\mathbf{b} \mathrm{S}-\mathrm{UMEC} 2 \mathrm{~B} / 3$ as cancer.

The Kappa statistic for the two raters were used to estimate the interobserver agreement. Kappa values $\leq 0.40,0.41$ to 0.75 , and $\geq 0.75$ were considered poor, good, and excellent, respectively [13]. $95 \%$ confidence intervals were calculated using the Wilson method. All analyses were performed using STATA software version 14.1 (Stata Corp. Texas, United States).

\section{Ethical considerations}

The study protocol adhered to the principles of the Declaration of Helsinki and was approved by the Ethics Committee of Showa University Koto Toyosu Hospital (IRB Registration No: 20T7016).

\section{Results \\ Esophagus}

A total of 88 esophageal squamous lesions were included in the study after excluding 29 cases with low quality images. Population characteristics are presented in $>$ Table 2 . Histopathological results were as follows: nine normal, 14 inflammation, 22 intraepithelial neoplasia, and $43 \mathrm{SCC}$. The diagnostic ability for esophageal squamous lesion was evaluated and summarized in - Table 3. The ability of UMEC to diagnose esophageal squamous lesions was calculated and is shown in $>$ Table 3 . The sensitivity, specificity, and accuracy of UMEC for the diagnosis of SCC were $84.5 \%, 84.9 \%$, and $84.7 \%$, respectively. The interobserver agreement, Kappa statistic $=0.51(95 \% \mathrm{Cl}$ : 0.35-0.66), was good. The sensitivity, specificity, and accuracy of UMEC for diagnosis of squamous neoplasms were $87.0 \%, 91.6 \%$, and $90.4 \%$, respectively. The interobserver agreement, Kappa statistic $=0.59$ (95\% Cl: 0.40-0.77), was good. When the diagnostic ability of UMEC for deep submucosal cancer was evaluated, the sensitivity, specificity, and accuracy were $68.2 \%, 94.4 \%$, and $91.5 \%$, respectively. The interobserver agreement, Kappa statistic $=0.56(95 \% \mathrm{Cl}: 0.32-0.80)$, was good.

\section{Stomach}

From 150 cases, 60 cases with low-quality images were excluded from this study. A total of 90 gastric lesions were included to this study. Population characteristics are presented
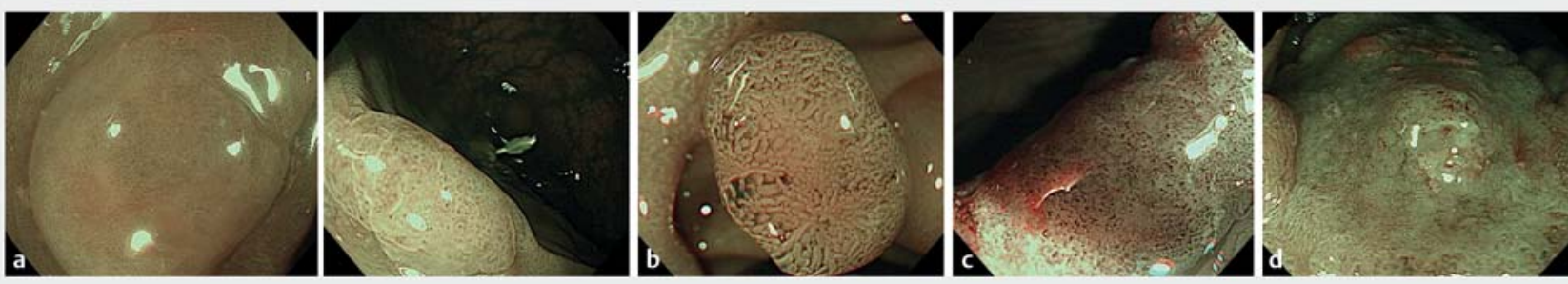

- Fig. 3 UMEC for colon (C-UMEC). a C-UMEC 1 are considered as hyperplastic polyp and sessile serrated polyp, b C-UMEC 2A as low-grade intramucosal neoplasia, c C-UMEC 2B as non-invasive, high-grade neoplasia/intramucosal carcinoma/carcinoma in situ (Tis), and superficial submucosal invasive carcinoma (SM-s: T1a; $<1,000 \mu \mathrm{m})$, and d C-UMEC 3 as deep submucosal invasive carcinoma (SM-d: T1 b; $\geq 1,000 \mu \mathrm{m})$. 
- Table 2 Patient clinicopathological characteristics.

\begin{tabular}{|c|c|c|c|}
\hline Variables & Esophagus $(n=88)$ & Stomach $(n=90)$ & Colon $(n=125)$ \\
\hline Age (year), mean (SD) & $65(13)$ & $75(12)$ & $64(13)$ \\
\hline \multicolumn{4}{|l|}{ Sex } \\
\hline - Male (\%) & $63(72 \%)$ & $67(74 \%)$ & $73(58 \%)$ \\
\hline - Female (\%) & $25(28 \%)$ & $23(26 \%)$ & $52(42 \%)$ \\
\hline $\begin{array}{l}\text { Macroscopic type of } \\
\text { cancer lesions }\end{array}$ & $\begin{array}{l}0-I=5 \\
0-I I a=8 \\
0-I I b=19 \\
0-I I c 11\end{array}$ & $\begin{array}{l}\|p+\| a=1 \\
\| a=11 \\
\|a+\| c=3 \\
\| c=24\end{array}$ & $\begin{array}{l}I s=15 \\
I s p=19 \\
I p=1 \\
\| a=20 \\
\| c=1\end{array}$ \\
\hline \multicolumn{4}{|l|}{ Treatment of cancer lesions } \\
\hline - Endoscopic resection & 48 & 39 & 22 \\
\hline - Surgery & 5 & 0 & 24 \\
\hline $\begin{array}{l}\text { Lesion diameter }(\mathrm{mm}) \\
\text { of cancer lesions, } \\
\text { median (IQR) }\end{array}$ & $10(5-22)$ & $17.5(10-30.5)$ & $11.0(6-39)$ \\
\hline Histopathology & $\begin{array}{l}\text { Normal }=9 \\
\text { Inflammatory change }=14 \\
\text { Intraepithelial neoplasia }=22 \\
\text { Squamous cell carcinoma }=43\end{array}$ & $\begin{array}{l}\text { Gastritis }=26 \\
\text { Adenoma }=25 \\
\text { Adenocarcinoma }=39 \\
\text { - Well-differentiated tubular }= \\
27 \\
\text { - Moderately differentiated } \\
\text { tubular }=12\end{array}$ & $\begin{array}{l}\text { Hyperplastic polyp (sessile serrated polyp) }=32 \\
\text { Low-grade intramucosal neoplasia }=47 \\
\text { Noninvasive high-grade neoplasia (intramuco- } \\
\text { sal carcinoma, carcinoma in situ) }=15 \\
\text { (Submucosal) carcinoma }=31\end{array}$ \\
\hline \multicolumn{4}{|l|}{ Invasion depth } \\
\hline - Intramucosal & $E P=21 / L P M=6 / M M=5$ & 31 & 15 \\
\hline - Shallow submucosal & 9 & 3 & 8 \\
\hline - Deep submucosal & 2 & 5 & 23 \\
\hline
\end{tabular}

- Table 3 Diagnostic yield of magnifying NBI applying UMEC for esophageal lesions.

\begin{tabular}{|c|c|c|c|c|c|c|}
\hline & $\begin{array}{l}\text { Sensitivity } \\
\%(95 \% \mathrm{Cl})\end{array}$ & $\begin{array}{l}\text { Specificity } \\
\%(95 \% \mathrm{Cl})\end{array}$ & $\begin{array}{l}\text { PPV } \\
\%(95 \% \mathrm{Cl})\end{array}$ & $\begin{array}{l}\text { NPV } \\
\%(95 \% \mathrm{Cl})\end{array}$ & $\begin{array}{l}\text { Accuracy } \\
\%(95 \% \mathrm{Cl})\end{array}$ & $\begin{array}{l}\text { Kappa value } \\
(95 \% \mathrm{Cl}) \\
P \text { value }\end{array}$ \\
\hline \multicolumn{7}{|c|}{ E-UMEC 1 vs $2+3$ (non-neoplastic vs neoplastic) } \\
\hline Endoscopist A & $91.3(77.4-97.4)$ & $90.8(85.8-92.9)$ & $77.8(65.9-83.0)$ & $96.7(91.5-99.0)$ & $90.9(83.6-94.1)$ & \multirow{2}{*}{$\begin{array}{l}0.59(0.40-0.77) \\
P<0.0001\end{array}$} \\
\hline Endoscopist B & $82.6(67.9-91.5)$ & $92.3(87.1-95.5)$ & $79.2(65.1-87.7)$ & $93.8(88.5-97.0)$ & $89.8(82.1-94.4)$ & \\
\hline \multicolumn{7}{|c|}{$\mathrm{E}-\mathrm{UMEC} 1+2 \mathrm{~A}$ vs $2 \mathrm{~B}+3$ (non-cancer vs cancer) } \\
\hline Endoscopist A & $73.3(66.1-75.2)$ & $97.7(90.1-99.6)$ & $97.1(87.4-99.5)$ & $77.8(71.7-79.3)$ & $85.2(77.8-87.1)$ & \multirow{2}{*}{$\begin{array}{l}0.51(0.35-0.66) \\
P<0.0001\end{array}$} \\
\hline Endoscopist B & $95.6(87.7-98.7)$ & $72.1(63.9-75.4)$ & $78.2(71.7-80 / 8)$ & $93.9(83.2-8.3)$ & $84.1(76.0-87.3)$ & \\
\hline \multicolumn{7}{|c|}{ E-UMEC $1+2$ vs 3 (Deep submucosal invasive cancer vs others) } \\
\hline Endoscopist A & $81.8(56.3-94.6)$ & $90.0(87.3-92.7)$ & $56.3(38.7-65.0)$ & $97.2(93.3-99.2)$ & $89.8(83.4-93.0)$ & \multirow{2}{*}{$\begin{array}{l}0.56(0.32-0.80) \\
P<0.0001\end{array}$} \\
\hline Endoscopist B & $54.5(33.6-62.0)$ & $98.7(95.7-99.8)$ & $85.7(52.8-97.4)$ & $93.8(91.0-94.8)$ & $93.2(87.9-95.0)$ & \\
\hline
\end{tabular}


- Table 4 Diagnostic yield of magnifying NBI applying UMEC for gastric lesions.

\begin{tabular}{|c|c|c|c|c|c|c|}
\hline & $\begin{array}{l}\text { Sensitivity } \\
\%(95 \% \mathrm{Cl})\end{array}$ & $\begin{array}{l}\text { Specificity } \\
\%(95 \% \mathrm{Cl})\end{array}$ & $\begin{array}{l}\text { PPV } \\
\%(95 \% \mathrm{Cl})\end{array}$ & $\begin{array}{l}\text { NPV } \\
\%(95 \% \mathrm{CI})\end{array}$ & $\begin{array}{l}\text { Accuracy } \\
\%(95 \% \mathrm{Cl})\end{array}$ & $\begin{array}{l}\text { Kappa value } \\
(95 \% \mathrm{CI}) \\
P \text { value }\end{array}$ \\
\hline \multicolumn{7}{|c|}{ S-UMEC $1 / 2 \mathrm{~A}$ vs $2 \mathrm{~B} / 3$ (non-cancer vs cancer) } \\
\hline Endoscopist A & $84.6(76.8-86.7)$ & $98.0(92.1-99.6)$ & $97.1(88.1-99.5)$ & $89.3(83.8-90.7)$ & $92.2(85.4-94.0)$ & \multirow{2}{*}{$\begin{array}{l}0.73(0.59-0.87) \\
P<0.001\end{array}$} \\
\hline Endoscopist B & $97.1(87.5-99.5)$ & $80.4(74.5-81.8)$ & $75.0(67.6-76.9)$ & $97.8(90.8-99.6)$ & $86.7(79.4-88.5)$ & \\
\hline
\end{tabular}

$\mathrm{NBI}$, narrow-band imaging; UMEC, unified magnifying endoscopic classification; PPV, positive predictive value; NPV, negative predictive value; $\mathrm{Cl}$, confidence interval.

- Table 5 Diagnostic yield of magnifying NBI applying UMEC for colonic lesions.

\begin{tabular}{|c|c|c|c|c|c|c|}
\hline & $\begin{array}{l}\text { Sensitivity } \\
\%(95 \% \mathrm{CI})\end{array}$ & $\begin{array}{l}\text { Specificity } \\
\%(95 \% \mathrm{Cl})\end{array}$ & $\begin{array}{l}\text { PPV } \\
\%(95 \% \mathrm{Cl})\end{array}$ & $\begin{array}{l}\text { NPV } \\
\%(95 \% \mathrm{CI})\end{array}$ & $\begin{array}{l}\text { Accuracy } \\
\%(95 \% \mathrm{Cl})\end{array}$ & $\begin{array}{l}\text { Kappa value } \\
(95 \% \mathrm{Cl}) \\
P \text { value }\end{array}$ \\
\hline \multicolumn{7}{|c|}{ C-UMEC 1 vs $2+3$ (non-neoplastic vs neoplastic) } \\
\hline Endoscopist A & $89.4(76.9-96.5)$ & $97.3(90.6-99.7)$ & $95.5(84.5-99.4)$ & $93.5(85.5-97.9)$ & $94.2(88.4-97.6)$ & \multirow{2}{*}{$\begin{array}{l}0.80 \\
(0.69-0.90) \\
P<0.001\end{array}$} \\
\hline Endoscopist B & $91.5(79.6-97.6)$ & $100(92.8-100)$ & $100(88.0-100)$ & $94.9(87.4-98.6)$ & $96.7(91.8-99.1)$ & \\
\hline \multicolumn{7}{|c|}{ C-UMEC $1+2 \mathrm{~A}$ vs $2 \mathrm{~B}+3$ (non-cancer vs cancer) } \\
\hline Endoscopist A & $76.1(61.2-87.4)$ & $77.2(66.4-85.9)$ & $66.0(51.7-78.5)$ & $84.7(74.3-92.1)$ & $76.8(68.4-83.9)$ & \multirow{2}{*}{$\begin{array}{l}0.63 \\
(0.49-0.77) \\
P<0.001\end{array}$} \\
\hline Endoscopist B & $82.6(68.6-92.2)$ & $93.7(85.8-97.9)$ & $88.4(74.9-96.1)$ & $90.2(81.7-95.7)$ & $89.6(82.9-94.3)$ & \\
\hline \multicolumn{7}{|c|}{ C-UMEC $1+2$ vs 3 (Deep submucosal invasive cancer vs others) } \\
\hline Endoscopist A & $91.3(72.0-98.9)$ & $95.1(88.9-98.4)$ & $80.8(60.6-93.4)$ & $98.0(92.9-99.8)$ & $94.4(88.8-97.7)$ & \multirow{2}{*}{$\begin{array}{l}0.66 \\
(0.48-0.83) \\
P<0.001\end{array}$} \\
\hline Endoscopist B & $69.6(47.1-86.8)$ & $100(94.7-100)$ & $100(71.3-100)$ & $93.6(87.2-97.4)$ & $94.4(88.8-97.7)$ & \\
\hline
\end{tabular}

in $>$ Table 2. Upon histopathological examination, 51 were diagnosed as non-cancer, and 39 as cancer. The sensitivity, specificity and accuracy of UMEC for the diagnosis of gastric cancer (S-UMEC 1/2A vs UMEC 2B/3) were calculated and shown in - Table 4. The overall sensitivity, specificity, and accuracy of UMEC for both endoscopists were $90.9 \%, 89.2 \%$, and $89.5 \%$, respectively. The interobserver agreement, Kappa statistic = 0.73 (95\% Cl: 0.59-0.87), was good.

\section{Colon}

From 150 cases, 25 cases with low-quality images were excluded from this study, and a total of 125 colonic lesions were included to this study. Population characteristics are presented in - Table 2. Histologically, 32 were diagnosed as hyperplastic polyps, 47 as adenomas, and 15 as high-grade dysplasia, 8 as SM-s adenocarcinoma, and 23 as SM-d adenocarcinoma. The diagnostic yield of UMEC for 1) non-cancer vs cancer, 2) nonneoplasm vs neoplasm, and 3) deep submucosal invasive cancer were evaluated and are summarized in $>$ Table 5 . The overall sensitivity, specificity, and accuracy of UMEC for colonic cancer were $79.4 \%, 85.5 \%$, and $83.2 \%$, respectively. The interobserver agreement, Kappa statistic $=0.63$ (95\% Cl: 0.49-0.77), was good. The overall sensitivity, specificity, and accuracy of UMEC for in the diagnosis of colonic neoplasms (C-UMEC 1 vs C-UMEC 2+3) were 90.6\%, 97.9\%, and 96.0\%, respectively. The interobserver agreement, Kappa statistic $=0.79(95 \% \mathrm{Cl}$ : 0.66-0.91), was good. Finally, the overall sensitivity, specificity, and accuracy of UMEC for diagnosis of deep submucosal invasive cancer (C-UMEC $1+2$ vs 3 ) were $80.5 \%, 97.6 \%$, and 94.4 $\%$, respectively. The interobserver agreement, Kappa statistic = 0.66 (95\% Cl: 0.49-0.83), was good.

\section{Discussion}

The diagnostic performance and accuracy of UMEC to identify neoplasms and carcinomas among endoscopically identified lesions was evaluated in this study. When compared to the gold standard histopathology, UMEC showed satisfactory accuracy in diagnosing non-neoplastic, intramucosal neoplasia, and deep submucosal invasive cancer.

The role of magnifying NBI differs in each organ. In the esophagus, it is used to analyze the histopathology of squamous epithelium and the invasion depth of the cancer. In the stomach, magnifying NBI plays a role in the assessment of the 
histopathology of the columnar epithelium, for the differentiation between non-cancer and cancer. Similar to the esophagus, in the colon, magnifying NBI is used to analyze the histopathology of columnar epithelium and the invasion depth of the cancer. Although these differences exist, applying the same categorization to each organ may be simpler and easy to understand. In addition, UMEC does not aim to replace the existing organ-specific classifications utilized by specialized expert endoscopists; however, a generalized use of a magnifying NBI diagnostic criteria common to the gastroinestinal tract may be more practical for non-expert endoscopists and general gastroenterologists, hence, the proposal of UMEC in the present study.

\section{Esophagus}

Since the introduction of IPCL Pattern Classification by Inoue in 2007 [14], IPCL pattern has been applied to estimate histopathological atypia by use of magnifying NBI [14]. By assessing the irregularity of IPCL, which refers to the changes in morphology such as dilation, tortuosity, change in caliber, and various shapes, magnifying NBI has been shown to accurately diagnose esophageal SCC $[15,16]$. Studies on the diagnostic performance of IPCL pattern classification and the invasion depth have shown satisfactory results, with over $80 \%$ rates [16-21]. In 2012, the Japan Esophageal Society (JES) established a classification of magnifying NBI findings to diagnose ESCC and its invasion depth of superficial ESCC [22]. This newly developed JES magnifying endoscopic classification is useful in estimating the invasion depth of superficial esophageal SCC and this classification has been used in clinical practice in Japan but not yet being standardized elsewhere outside of Japan.

From our experience, auxiliary criteria of assessing avascular area and reticular pattern vessels are subjective and its interpretation is not standardized or categorized. We have simplified the criteria as described in $>$ Table 1 . Therefore, we recommend focusing on IPCL morphology. By utilizing UMEC, the overall accuracy for diagnosis of SCC was $84.7 \%$ and the overall accuracy for diagnosis of deep submucosal invasion was $91.5 \%$, which seems to be comparable to previous studies.

\section{Stomach}

By utilizing magnifying NBI, the standard method of evaluating gastric lesions, VS classification [3], and the diagnostic strategy for gastric mucosal cancer, MESDA-G [4], have been created to simplify the process of diagnosis and improve accuracy. Literature reporting on the diagnostic performance of magnifying NBI with VS classification in the diagnosis of early gastric cancer have shown satisfactory to excellent accuracy rates, ranging from $79 \%$ to more than $95 \%$ [23-25]. In the present study, through an adaptation of MESDA-G, UMEC led to good diagnostic accuracy (overall accuracy for both endoscopists: $89.5 \%$ ) and interobserver agreement for distinguishing gastric cancer from non-malignant cases, coinciding with previous reports.

In differentiating intramucosal cancer from submucosal invasive cancer, there is some evidence that white light endoscopy and magnifying NBI (especially in differentiated gastric cancer) is useful in diagnosing the invasion depth [26-29]; however, consensus is yet to be reached on this. This is because NBI shows only the superficial mucosa for early gastric cancer and invasive tissue is often not exposed at the surface and mucosal structures remain, even when the cancer invades the submucosa [30], hence, making it difficult to differentiate intramucosal cancer from submucosal invasive cancer. For this reason, the difference between gastric S-UMEC 2B and 3 could not be evaluated in the present study.

Furthermore, undifferentiated cancer with non-cancerous epithelium on the mucosal surface as well as pale mucosal lesion with tissue diagnosis of signet-ring cell carcinoma are difficult to diagnose by magnifying NBI, since non-cancerous epithelium remains on the mucosal surface. This implies that these specific lesions should also be regarded as limitations in applying UMEC in the stomach [25].

\section{Colon}

To date, several magnifying NBI classifications of colorectal tumors have been advocated. Sano et al were the first to publish a magnifying NBI classification known as the Capillary Pattern classification in 2006 [6]. Based on this, other magnifying NBI classifications (Hiroshima [7, 31], Showa [8], and jikei [9] classifications) were proposed. In 2012, the NBI International Colorectal Endoscopic (NICE) classification [10] was established as a simple classification which can be applied using NBI with or without optical magnification, and is now being used worldwide. However, as histopathological criteria of curative endoscopic resection for early CRC are being clarified, endoscopists are required to diagnose the invasion depth accurately and obtain appropriate histopathological materials by en bloc EMR or ESD. Therefore in 2016, the JNET classification [12] was proposed by the Japan NBI Expert Team, aiming to unify previous classifications which provides accurate qualitative and quantitative diagnosis linking to the appropriate treatment strategy including polypectomy, piecemeal/en bloc EMR, ESD, and surgery [32]. Several studies have shown its diagnostic performance and clinical usefulness $[33,34]$ and it is already widespread in Japan, and the International Evaluation of Endoscopy classification JNET (IEE-JNET), a collaborative research project by ESGE and JGES, is currently underway. Thus, our new UMEC classification, the main objective of which is to unify classification among three organs, basically adapted the JNET classification.

In our study, the overall accuracy for diagnosis of CRC was $93.3 \%$ and the overall accuracy for diagnosis of deep submucosal invasion was $95.1 \%$. However, the accuracy for type 2B lesions was relatively lower with poor intraobserver agreement, similar to the previous studies [34]. Becausee chromoendoscopy, with the use of crystal violet staining, can provide a more reliable diagnosis for invasion depth than IEE [35], it is recommended to also perform chromoendoscopy for Type 2B lesions [34]. In other words, due to the time associated with chromoendoscopy, UMEC is clinically useful as a previous step to select which lesion should undergo chromoendoscopy as part of the diagnostic strategy. 


\section{Limitations}

At this point, however, certain study limitations must be acknowledged. This was a retrospective observational study, which potentially included selection bias. Moreover, this was an image review study in a single center, and a larger number of lesions are needed to further validate the results obtained. In addition, direct comparison of the diagnostic yield of previous criteria was not done in this study, and a prospective study with a clinical setting is needed to validate these study results.

\section{Conclusions}

In all, given its good diagnostic accuracy in this pilot study, UMEC appears to be a simple and practically acceptable classification, particularly to general gastroenterologists. Furthermore, generalized use of magnifying NBI diagnostic criteria may be achieved, hence, UMEC deserves further evaluation in future studies.

\section{Acknowledgements}

The authors thank all of the patients and staff for their participation and contributions to this study.

\section{Competing interests}

Dr. Inoue is an advisor for Olympus Corporation and Top Corporation. He has received educational grants from Olympus Corporation and Takeda Pharmaceutical Company.

\section{References}

[1] Tsurudome I, Miyahara R, Funasaka K et al. In vivo histological diagnosis for gastric cancer using endocytoscopy. World J Gastroenterol 2017; 23: 6894-6901

[2] Abad MRA, Inoue H, Ikeda $\mathrm{H}$ et al. Utilizing fourth-generation endocytoscopy and the 'enlarged nuclear sign' for in vivo diagnosis of early gastric cancer. Endosc Int Open 2019; 7: E1002-e1007

[3] Yao K, Anagnostopoulos GK, Ragunath K. Magnifying endoscopy for diagnosing and delineating early gastric cancer. Endoscopy 2009; 41: 462-467

[4] Muto M, Yao K, Kaise M et al. Magnifying endoscopy simple diagnostic algorithm for early gastric cancer (MESDA-G). Digestive endoscopy : official journal of the Japan Gastroenterological Endoscopy Society 2016; 28: 379-393

[5] Machida H, Sano Y, Hamamoto Y et al. Narrow-band imaging in the diagnosis of colorectal mucosal lesions: a pilot study. Endoscopy 2004; 36: 1094-1098

[6] Sano Y, Horimatsu T, Fu Kl et al. Magnifying observation of microvascular architecture of colorectal lesions using a narrow-band imaging system. Digest Endosc 2006; 18: S44-S51

[7] Kanao H, Tanaka S, Oka S et al. Narrow-band imaging magnification predicts the histology and invasion depth of colorectal tumors. Gastrointest Endosc 2009; 69: 631-636
[8] Wada Y, Kudo SE, Kashida H et al. Diagnosis of colorectal lesions with the magnifying narrow-band imaging system. Gastrointest Endosc 2009; 70: 522-531

[9] Nikami T, Saito S, Tajiri $\mathrm{H}$ et al. The evaluation of histological atypia and depth of invasion of colorectal lesions using magnified endoscopy with narrow-band imaging. Gastroenterol Endosc 2009; 51: 1019

[10] Hewett DG, Kaltenbach T, Sano Y et al. Validation of a simple classification system for endoscopic diagnosis of small colorectal polyps using narrow-band imaging. Gastroenterology 2012; 143: 599-607

[11] Hayashi N, Tanaka S, Hewett DG et al. Endoscopic prediction of deep submucosal invasive carcinoma: validation of the narrow-band imaging international colorectal endoscopic (NICE) classification. Gastrointest Endosc 2013; 78: 625-632

[12] Sano Y, Tanaka S, Kudo SE et al. Narrow-band imaging (NBI) magnifying endoscopic classification of colorectal tumors proposed by the Japan NBI Expert Team. Digest Endosc 2016; 28: 526-533

[13] Kirch W. Encylopedia of Public Health. Springer Netherlands; 2008

[14] Inoue H. Endoscopic diagnosis of tissue atypism (EA) in the pharyngeal and esophageal squamous epithelium; IPCL pattern classification and ECA classification. Kyobu Geka 2007; 60: 768-775

[15] Inoue H, Kaga M, Ikeda $\mathrm{H}$ et al. Magnification endoscopy in esophageal squamous cell carcinoma: a review of the intrapapillary capillary loop classification. Ann Gastroenterol 2015; 28: 41-48

[16] Yu T, Geng J, Song W et al. Diagnostic accuracy of magnifying endoscopy with narrow band imaging and its diagnostic value for invasion depth staging in esophageal squamous cell carcinoma: a systematic review and meta-analysis. BioMed Res Int 2018; 2018: 8591387

[17] Lee CT, Chang CY, Lee YC et al. Narrow-band imaging with magnifying endoscopy for the screening of esophageal cancer in patients with primary head and neck cancers. Endoscopy 2010; 42: 613-619

[18] Nagai K, Ishihara R, Ishiguro $S$ et al. Endoscopic optical diagnosis provides high diagnostic accuracy of esophageal squamous cell carcinoma. BMC Gastroenterol 2014; 14: 141

[19] Goda K, Tajiri H, Ikegami M et al. Magnifying endoscopy with narrow band imaging for predicting the invasion depth of superficial esophageal squamous cell carcinoma. Dis Esophagus 2009; 22: 453-460

[20] Ebi M, Shimura T, Yamada T et al. Multicenter, prospective trial of white-light imaging alone versus white-light imaging followed by magnifying endoscopy with narrow-band imaging for the real-time imaging and diagnosis of invasion depth in superficial esophageal squamous cell carcinoma. Gastrointest Endosc 2015; 81: 1355-361. e1352

[21] Lee MW, Kim GH, Hoseok I et al. Predicting the invasion depth of esophageal squamous cell carcinoma: comparison of endoscopic ultrasonography and magnifying endoscopy. Scand J Gastroenterol 2014; 49: 853-861

[22] Oyama T, Inoue $\mathrm{H}$, Arima $\mathrm{M}$ et al. Prediction of the invasion depth of superficial squamous cell carcinoma based on microvessel morphology: magnifying endoscopic classification of the Japan Esophageal Society. Esophagus 2017; 14: 105-112

[23] Ezoe $\mathrm{Y}$, Muto M, Horimatsu T et al. Magnifying narrow-band imaging versus magnifying white-light imaging for the differential diagnosis of gastric small depressive lesions: a prospective study. Gastrointest Endosc 2010; 71: 477-484

[24] Ezoe $\mathrm{Y}$, Muto $\mathrm{M}$, Uedo $\mathrm{N}$ et al. Magnifying narrowband imaging is more accurate than conventional white-light imaging in diagnosis of gastric mucosal cancer. Gastroenterology 2011; 141: 2017-2025. e2013

[25] Yao K, Doyama H, Gotoda T et al. Diagnostic performance and limitations of magnifying narrow-band imaging in screening endoscopy of early gastric cancer: a prospective multicenter feasibility study. Gastric Cancer 2014; 17: 669-679 
[26] Abe S, Oda I, Shimazu T et al. Depth-predicting score for differentiated early gastric cancer. Gastric Cancer 2011; 14: 35-40

[27] Choi J, Kim SG, Im JP et al. Endoscopic prediction of tumor invasion depth in early gastric cancer. Gastrointest Endosc 2011; 73: 917-927

[28] Li HY, Dai J, Xue HB et al. Application of magnifying endoscopy with narrow-band imaging in diagnosing gastric lesions: a prospective study. Gastrointest Endosc 2012; 76: 1124-1132

[29] Kobara H, Mori H, Fujihara S et al. Prediction of invasion depth for submucosal differentiated gastric cancer by magnifying endoscopy with narrow-band imaging. Oncol Rep 2012; 28: 841-847

[30] Uedo N, Fujishiro M, Goda K et al. Role of narrow band imaging for diagnosis of early-stage esophagogastric cancer: current consensus of experienced endoscopists in Asia-Pacific region. Digest Endosc 2011; 23: 58-71

[31] Hirata M, Tanaka S, Oka S et al. Magnifying endoscopy with narrow band imaging for diagnosis of colorectal tumors. Gastrointest Endosc 2007; 65: 988-995
[32] Sano Y, Hirata D, Saito Y. Japan NBI Expert Team classification: Narrow-band imaging magnifying endoscopic classification of colorectal tumors. Dig Endosc 2018; 30: 543-545

[33] Komeda Y, Kashida H, Sakurai T et al. Magnifying narrow band imaging (NBI) for the diagnosis of localized colorectal lesions using the Japan NBI Expert Team (JNET) classification. Oncology 2017; 93: 4954

[34] Sumimoto K, Tanaka S, Shigita K et al. Clinical impact and characteristics of the narrow-band imaging magnifying endoscopic classification of colorectal tumors proposed by the Japan NBI Expert Team. Gastrointest Endosc 2017; 85: 816-821

[35] Sakamoto T, Nakajima T, Matsuda T et al. Comparison of the diagnostic performance between magnifying chromoendoscopy and magnifying narrow-band imaging for superficial colorectal neoplasms: an online survey. Gastrointest Endosc 2018; 87: 1318-1323 